\title{
СРАВНИТЕЛЬНАЯ ХАРАКТЕРИСТИКА ОРГАНИЗАЦИОННО-ЭКОНОМИЧЕСКИХ УСЛОВИЙ РАЗВИТИЯ ТУРИЗМА В РОССИИ И ЗА РУБЕЖОМ
}

В статье рассмотрен зарубежный опьтт государственного регулирования развития рылнка туристических услуг и возножность его применения в России, приводятся международные организации, которые занимаются разработкой национальных программ развития туризма, выявляются проблемы развития российской сферы туризма, предлагается несколько вариантов решения данныхх проблем, приводятся институты, регулировавиие сферу туризма в СССР и после его распада, проводится анализ особенностей развития рынка туристических услуг в России по сравнению с зарубежсными странами согласно базовым критериям развития туризма и туристской индустрии в условиях глобализачии и перехода к постиндустриальному обществу.

Ключевые слова: туризм, туристическая отрасль, туристский рынок, индустрия туризма, туристический рынок, туристская дестинация, индустрия гостеприимства, туристская сфера, туристский продукт, рынок туристических услуг.

\section{Danil Shepelev, Valentina Lovyannikova COMPARATIVE CHARACTERISTIC OF ORGANIZATIONAL AND ECONOMIC CONDITIONS OF DEVELOPMENT OF TOURISM IN RUSSIA AND ABROAD}

The article considers the foreign experience of state regulation of the tourism market and the possibility of its application in Russia, international organizations that are engaged in the development of national programs of tourism development, identifies the problems of development of the Russian tourism sector, offers several solutions to these problems, the institutions that regulate the tourism sector in the USSR and after its collapse, the analysis of features of development of the market of tourist services in Russia in comparison with foreign countries according to basic criteria of development of tourism and the tourist industry in the conditions of globalization and transition to postindustrial society is carried out.

Key words: tourism, tourism industry, tourism market, tourist destination, hospitality industry, tourism product, tourism services market.

Bведениe /Introduction. На сегодняшний день темпы развития туристической отрасли существенно выше, чем несколько десятилетий назад. Ввиду этого особую актуальность приобретает анализ развития данной сферы в нашем государстве и за границей. Как показывает опыт других стран, эффективность и успешность развития туристической отрасли прямо пропорциональны тем усилиям, которые государство готово приложить с этой целью.

Следует подчеркнуть, что в отечественной научной литературе сегодня недостаточно проработаны вопросы соотнесения особенностей туристической индустрии Российской Федерации с ее предполагаемой траекторией развития в зарубежных странах. В связи с этим значение данного исследования только повышается. Лишь в немногочисленных публикациях преимущественно зарубежных авторов частично рассматривается интересующая данная проблематика. Так, в работе Ч. Ч. Ли и Ч. П. Чанга, проведенной с использованием статистических методов, установлены сравнительные казуальные отношения между развитием туристической сферы и улучшением состояния экономики в государствах ОЭСР, а также в тех странах, которые не входили в состав ОЭСР с 1990 по 2002 годы [6]. 
Целью исследования выступает сравнительный анализ основных особенностей развития туризма в России и за рубежом. Несмотря на то, что такая постановка вопроса может на первый взгляд показаться базовой, более того, можно было бы ожидать подробного рассмотрения указанной темы даже в учебной, не говоря о научной, литературе, все же аспекты сравнительного анализа специфики развития туризма в России и за рубежом являются мало освещенными в исследованиях.

Для достижения поставленной цели исследования необходимо решить следующие задачи:

- $\quad$ рассмотреть систему государственного регулирования и поддержки развития туризма в России в контексте опыта зарубежных стран;

- провести сравнительный анализ особенностей развития индустрии туризма и гостеприимства в России и за рубежом на современном этапе развития индустрии.

Maтериалы и методы / Materials and methods. В качестве методов решения задач исследования использовались историко-генетический подход к развитию туризма в России, сравнительный анализ и контент-анализ для всестороннего раскрытия темы, также изучен опыт развития рынка туристических услуг таких зарубежных стран, как Великобритания, Ирландия, Испания, Италия и Норвегия. Объъктом исследования является туристический рынок РФ и некоторых зарубежных стран.

Pезультаты и обсуждение / Results and discussion. Специфический характер туристической индустрии обусловлен процессами глобализации, а также обширным кругом отношений, участниками которых становятся лица при организации туристских поездок. Многообразие таких отношений есть причина проблем с нормативным урегулированием рассматриваемой сферы. Все развитые в области туризма страны предусматривают в своем государственном аппарате специальные ведомства, в компетенцию которых входит формирование и внедрение государственных программ развития туристской индустрии. В частности, в Италии таким ведомством является ENIT, в Ирландии указанными вопросами занимается Irish Board, а в Испании подобный орган называют Turespana. С помощью данных ведомств, разрабатывающих привлекательные предложения и туристские программы, названные страны не испытывают недостатка в туристах.

В советский период индустрия туризма регулировалась посредством нескольких организаций, среди которых: Государственный комитет по иностранному туризму, Центральный совет по туризму и экскурсиям ВЦСПС, а также Бюро международного молодежного туризма «Спутник». Невзирая на тот факт, что Бюро и Центральный совет представляли собой общественные организации, государство являлось неизменным монополистом на советском туристическом рынке. Рассматривая часть представленных органов в туристском обмене, можно привести следующие данные: доля Госкоминтуриста составляла $85 \%$, на ЦСТЭ ВЦСПС приходилось 10 \%, а показатель «Спутника» составлял лишь $5 \%$ от общего объема.

Распад Советского Союза и переход к рыночной модели экономики значительно отразились и на сфере туризма. Рассмотренные выше организации прошли реорганизацию и теперь не относились к ведомствам, входящим в структуру государственного аппарата России. Их организационно-правовой формой стали акционерные общества, осуществляющие свою деятельность в качестве обыкновенных туристских фирм.

В течение длительного периода вопрос относительно формирования специального государственного органа, отвечающего за становление туристической индустрии, оставался открытым. Через некоторое время в структуре государственного аппарата Российской Федерации было создано Министерство культуры и туризма, в дальнейшем разделенное на два автономных органа, каждый из которых рассматривал свой круг вопросов. Так, в компетенцию Министерства культуры входило разрешение вопросов, касающихся культурной жизни страны, а Комитет по туризму отвечал за развитие туристской индустрии. 
Ближе к концу 90-х гг. ведомство, занимающееся вопросами туризма, снова было реорганизовано в Министерство по физической культуре, спорту и туризму [5]. Существенных структурных изменений при этом не последовало, потому как в основу нового органа легла структура Комитета по туризму, действовавшего ранее.

Тем не менее следует подчеркнуть, что функционирование ведомства, приоритетным направлением работы которого являлась спортивная деятельность и только потом туристическая сфера, было недостаточно эффективным для индустрии туризма. Когда круг вопросов, входящих в компетенцию ведомства, ограничивается какой-либо одной областью, это значительно повышает результативность его работы и отражает важность этой области в жизни государства и его институтов.

Согласно положениям Гаагской декларации по туризму, все государственные ведомства, ответственные за развитие сферы туризма, должны находиться на одной ступени с органами, рассматриваюшими другие важные для государства сегменты экономики.

На сегодняшний день все существенные вопросы, касающиеся туристкой индустрии, разграничены между различными ведомствами, что на практике приводит к множеству сложностей и проблем. Например, функционирующее с 2004 года Агентство по туризму разрабатывает и реализует массовую кампанию с целью развития внутригосударственного туризма, тогда как в это же время Министерство транспорта повышает оплату за перевозки, что минимизирует все усилия первой организации.

Опыт других стран показывает, что разрешение рассматриваемой проблемы может быть довольно успешным. В частности, в Соединенных Штатах деятельность Управления по туризму с целью становления внутригосударственного туризма осуществляется с участием специального органа - консультационного совета, состоящего из представителей других важных промышленных сфер. Интересен также опыт Франции, где каждое из десяти министерств обязуется выплачивать определенную сумму из своего бюджета для развития туризма в государстве [4].

Дискуссии о положении и соотнесении развития индустрии туризма и гостеприимства России с зарубежными странами являются актуальными, особенно с учетом некоторого прогресса России в рейтинге Travel and Tourism Competitiveness Report WEF в последние годы, поскольку страна поднялась с 68 места в 2007 г. до 45 места в 2015 г.

Проведем сравнительный анализ особенностей развития туризма в России и за рубежом по основным критериям, многие из которых являются базовыми с точки зрения сущности туризма и туристской индустрии, но приобретают особую важность в условиях нарастающей глобализации и перехода к постиндустриальному обществу.

1. Баланс при развитии туриндустрии в разных регионах государства. Наше государство отличается выраженным межрегиональным дисбалансом при развитии туристской отрасли. Подобная несбалансированность характерна и для большей части других государств, поскольку туризм по определению предусматривает, что туристы едут в места наибольшей симпатии, однако именно для России характерна большая выраженность централизации предпочтений въездных туристов, что легко прослеживается в статистике и рейтингах мест для посешения туристов. По мере развития въездного туризма несбалансированность регионального экономического роста, как правило, начинает снижаться, возникают вторичные центры притяжения туристов

2. Внутриотраслевая сбалансированность индустрии туризма и гостеприимства. Для России более характерны диспропорции между уровнями развитости различных сегментов индустрии туризма и гостеприимства. В начальной и промежуточной стадии активного развития туризма имеет место неравномерный рост и насыщение спроса в различных подотраслях индустрии туризма и гостеприимства, в то время как для зарубежных стран более характерно достижение большей сбалансированности инду- 
стрии туризма и гостеприимства в виде функционирования полноценных кластеров. Большой конкурентный недостаток России заключается в том, что во многих видах туризма, зависимых от состояния инфраструктуры, имеют место провалы в уровне, что приводит к размыванию туристских впечатлений.

3. Видовое разнообразие туризма. Диверсификация туристских продуктов в России включает более полное развитие массовых туристских продуктов [1]. Главной причиной этого является невозможность достижения критически необходимого уровня платежеспособного спроса. Для зарубежных стран характерна меньшая диверсификация видов туризма и представленность комбинированных туров.

4. Маркетинговое продвижение территорий: DMO (Destination Marketing Organization) и конвеншн-бюро. Исследования показывают, что в зарубежных странах структуры типа DMO встречаются чаще, а лучшие практики в сфере продвижения территорий используются шире [7]. Ярким примером одной из ведущих структур DMO общенационального типа является Visit Britain, которая составляет подробные аналитические отчеты по более чем двадцати странам, из которых в Великобританию приезжает наибольшее количество туристов. Функционирование таких мощных аналитических структур, подробно изучающих национальные портреты потребителей, является несомненным экспертным преимуществом зарубежных стран, в особенности Испании и Великобритании. Россия в условиях догоняющего развития ставит перед собой более скромные задачи по минимальному ознакомлению потенциальных туристов со своими ресурсами. Работа по этому критерию ведется в направлении преодоления стереотипов и опасений со стороны туристов.

5. Уровень сервиса и сервисоориентированности в туризме и гостеприимстве. В зарубежных странах компании индустрии туризма и гостеприимства учитывают более широкую палитру аспектов сервисного менеджмента в своих бизнес-процессах, нежели компании индустрии туризма в России [3]:

1) туристы в зарубежных странах более внимательны к аспектам безопасности и рискам в своих поездках, восприятие безопасности более существенно влияет на их потребительские предпочтения и даже на то, каким образом они планируют маршруты своих туристских поездок, включая вопросы безопасности в условиях городской среды и неблагополучных районов;

2) для развитых стран характерно повышенное внимание к категории пожилых туристов [2]. Для пожилых туристов свойственны более длительные сроки пребывания и гораздо более высокая вероятность повторного посещения.

6. Подготовка кадров в туризме, их специализация, сертификация, профессионализация. Зарубежным странам свойственна бо́льшая специализация и профессионализация кадров, а также более длительные периоды обучения, чем в России. Не только потому, что это некий общественный императив, но и по той причине, что служебные функции многих должностей как в проектировании и продвижении туристских продуктов, так и в туристском развитии территорий предъявляют более высокие требования к кандидатам. В зарубежных странах уже сложились целые образовательные кластеры в сфере туризма, тогда как в России они только формируются.

7. Степень развития консалтинга в туризме. Консалтинг является во многом индикативной подотраслью индустрии туризма и гостеприимства, поскольку он появляется на такой стадии формирования этой индустрии (как правило, на стадии развития кластеров), когда уже накоплена некоторая критическая масса платежеспособной потребности в профессиональной экспертизе и наладке бизнес-процессов в отрасли. 
По этому критерию зарубежные страны находятся далеко впереди России с точки зрения наличия «суперспециалистов» и визионеров, которые способны в рамках туристских кластеров быть важным фактором конкурентоспособности. Это происходит в течение последних 20 лет в ведущих странах в области туризма благодаря стратегическому, концептуальному консультированию на стадии проектирования бизнеса, а также оптимизации отдельных бизнес-процессов в рамках так называемого PSOM (Professional Service Operations Management).

Если консалтинг продуктивен, то в индустрии туризма и гостеприимства консалтинг увеличивает прибыльность бизнеса, а бизнес видит положительную отдачу от консалтинга и еще в большей степени его использует. Такие эффекты восходящей спирали развития индустрии туризма и гостеприимства наблюдаются в особенности в Испании и Великобритании.

Заключение /Conclusion. На основании проведенного анализа можно сформулировать вывод, что развитие рынка туристических услуг в России имеет ряд проблем, решение которых нам видится в содействии становлению туризма со стороны государства, создании благоприятных условий для его дальнейшего развития, а также формировании условий для институционализации на основе опыта зарубежных стран. Необходимо определиться с тем, элементы международного опыта каких стран с наибольшей вероятностью или желательностью могли бы выступать в качестве модели для прогнозирования тенденций российской индустрии туризма и гостеприимства.

\section{ЛИТЕРАТУРА И ИНТЕРНЕТ-РЕСУРСЫ}

1. Benur A. M., Bramwell B. Tourism product development and product diversification in destinations // Tourism Management. Vol. 50. Pp. 213-224.

2. Chen S. C., Shoemaker S. Age and cohort effects: The American senior tourism market // Annals of Tourism Research. Vo1. 48. Pp. 58-75.

3. Ilkevich S. Service Management Issues in Tourism and Hospitality in Russia: Some Lessons from International Studies, Proceedings of International Conference // Tourism in Transition Economies: Issues and Challenges for Destination Competitiveness. Caceres, Spain, 14-15 September 2015. Pp. 36-40.

4. Илькевич С. В. Сравнительный анализ особенностей развития индустрии туризма в экономически развитых и развивающихся странах // Сервис в России и за рубежом. 2016. Т. 10. Вып. 09 (70). С. 15-27.

5. Калинина Л. Е. Государственное управление туризмом: традиционно вместе со спортом // Туризм: право и экономика. 2008. № 3. С. 18-20.

6. Lee Ch.-Ch., Chang Ch.-P. Tourism development and economic growth: A closer look at panels // Journal of Tourism Management. Vol. 29. Issue 1. Pp. 180-192.

7. Pike S., Page S. Destination Marketing Organizations and destination marketing: A narrative analysis of the literature // Tourism Management. Vol. 41. Pp. 1-26.

\section{REFERENCES AND INTERNET RESOURCES}

1. Benur A. M., Bramwell B. Tourism product development and product diversification in destinations // Tourism Management. Vol. 50. Pp. 213-224.

2. Chen S. C., Shoemaker S. Age and cohort effects: The American senior tourism market // Annals of Tourism Research. Vol. 48. Pp. 58-75.

3. Ilkevich S. Service Management Issues in Tourism and Hospitality in Russia: Some Lessons from International Studies, Proceedings of International Conference // Tourism in Transition Economies: Issues and Challenges for Destination Competitiveness, Caceres, Spain, 14-15 September 2015. Pp. 36-40.

4. Il'kevich S. V. Sravnitel'nyj analiz osobennostej razvitiya industrii turizma v ehkonomicheski razvityh i razvivayushchihsya stranah (Comparative analysis of features of tourism industry development in economically developed and developing countries) // Servis v Rossii i za rubezhom. 2016. T. 10. No. 09 (70). S. 15-27.

5. Kalinina L. E. Gosudarstvennoe upravlenie turizmom: tradicionno vmeste so sportom (The state administration of tourism: traditionally, along with sport) // Turizm: pravo i ehkonomika, 2008. No 3. S. 18-20. 
6. Lee Ch.-Ch., Chang Ch.-P. Tourism development and economic growth: A closer look at panels // Journal of Tourism Management. Vol. 29. Issue 1. Pp. 180-192.

7. Pike S., Page S. Destination Marketing Organizations and destination marketing: A narrative analy sis of the literature // Tourism Management. Vol. 41. Pp. 1-26.

\section{СВЕДЕНИЯ ОБ АВТОРАХ}

Шепелев Данил Романович, магистрант кафедры экономики и внешнеэкономической деятельности ФГАОУ ВО «Северо-Кавказский федеральный университет». E-mail: danishepelev@yandex.ru

Ловянникова Валентина Викторовна, кандидат экономических наук, доцент кафедры экономики и внешнеэкономической деятельности ФГАОУ ВО «Северо-Кавказский федеральный университет». E-mail: valentlov@mail.ru

\section{INFORMATION ABOUT AUTHORS}

Danil Shepelev, graduate student of the Department of Economics and foreign economic activities, North-Caucasian Federal University. E-mail: danishepelev@yandex.ru

Valentina Lovyannikova, candidate of economic Sciences, associate Professor of Economics and foreign economic activities, North-Caucasian Federal University. E-mail: valentlov a mail.ru 